Javier García Algarra

Mapa de París con las siete centrales telefónicas y sus zonas de servicio en 1906.
Javier García Algarra

Ingeniero de Telecomunicación UPM. Máster Historia del Arte UNED.

Doctorado en Historia UNED.

Profesor colaborador asociado.

Centro Universitario de Tecnología y Arte Digital (U-TAD)

\title{
Arquitectura telefónica clásica El edificio industrial anuncio
}

Palabras clave: arquitectura industrial, telefonía, central telefónica, Bell system, iconografia.

La telefonía ha sido una de los servicios urbanos que más esfuerzo ha invertido en ocultar la infraestructura necesaria para su funcionamiento. Las centrales, que son contenedores técnicos de equipos, tuvieron que instalarse en el centro de las ciudades por necesidades técnicas. Desde los inicios del negocio se procuró que los edificios se pareciesen lo más posible alos del entorno en el que se emplazaban. Esto ha hecho que recibieran poca atención entre los investigadores de la arquitectura industrial. Externamente no parecen una factoría y el acceso a su interior, donde este carácter se revela de forma descarnada, está muy limitado al personal de las compañias propietarias. En este artículo se describe cómo se elaboraron las ideas que guiaron el desarrollo de la arquitectura telefónica en su periodo clásico, y cómo ese modelo de origen estadounidense se implantó en España a partir de 1924.

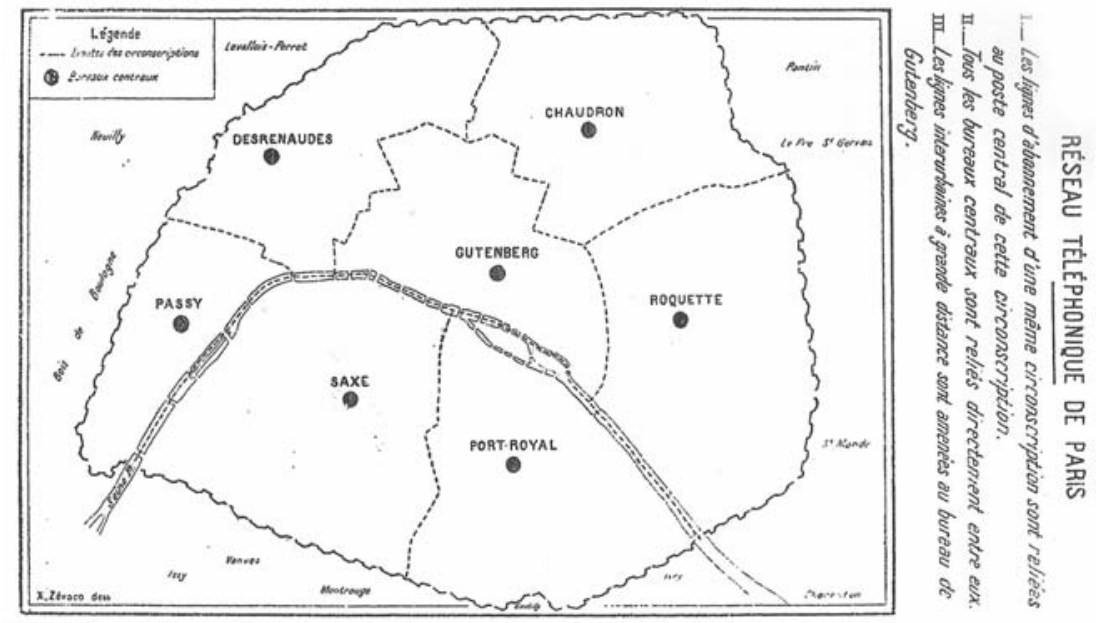

\section{Introducción}

Las centrales telefónicas son edificios industriales cuya naturaleza se ocultó de manera deliberada durante décadas. A diferencia de las grandes factorías, tuvieron que construirse en el interior de las ciudades. Una restricción técnica impedía llevarlas al extrarradio, la distancia máxima de la central al domicilio de los clientes estaba en un rango máximo de 3 a 5 kilómetros. Esto obligaba a situarlas cerca del centro para poder dar servicio a la mayor superficie urbana posible.

Nos encontramos ante pequeñas factorias emplazadas en los cascos históricos, sobre solares de precio elevado y rodeadas de entornos monumentales. Dos ejemplos españoles de finales de los años 20 permiten comprender esta peculiaridad. La central de Málaga se sitúa al pie de la Catedral. La de Sevilla, en la Plaza Nueva, a escasos metros del palacio plateresco del Ayuntamiento. Ninguno de estos edificios tiene aspecto fabril, sin embargo su distri- bución interna, estructura y métodos constructivos fueron los propios de la industria.

Si se compara la arquitectura de este negocio con la de otros de función parecida no hay muchos paralelos. Por ejemplo, el Cable Building, de McKim, Mead \& White (1894), contenía la maquinaria electromecánica de una línea de tranvías en Nueva York y en su aspecto exterior no se diferenciaba de otros grandes edificios comerciales de Manhattan. Sin embargo, la distribución eléctrica es un servicio que antecedió en su desarrollo al teléfono, con subestaciones y transformadores dentro de las ciudades, pero que nunca hizo esfuerzos por ocultarlos.

¿Por qué la telefonía adoptó esta solución? Lewis Mumford escribió que "la ciudad fomenta el arte y es arte, la ciudad crea el teatro y es teatro" (Mumford 1932:85). En este artículo se describe la política de imagen que asignó a las centrales el papel de edificios anuncio en el escenario urbano. 

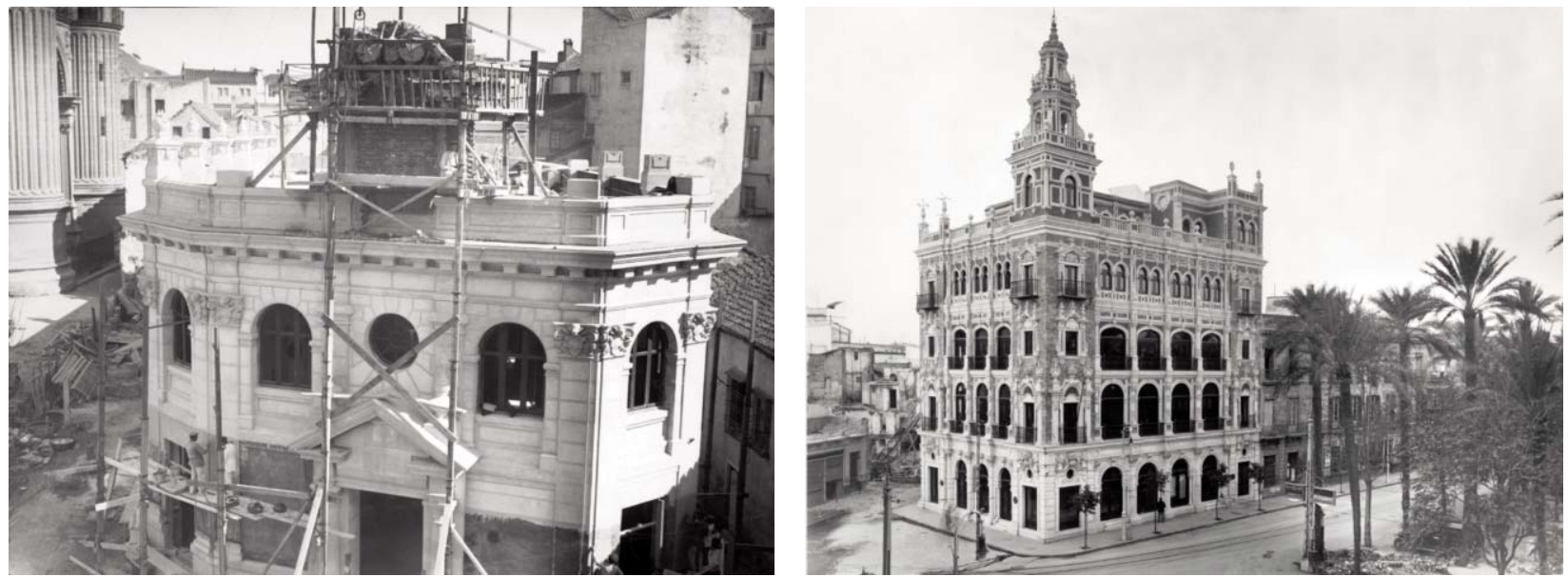

Izquierda. Construcción de la central telefónica de Málaga, 1928.

Derecha. Central de Sevilla, 1928.

\section{Caracteristicas de la arquitectura tele- fónica}

"La Arquitectura Telefónica tiene como misión la construcción de edificios destinados a albergar las instalaciones telefónicas y servicios que llevan anejos". (Vega 1945: 2).

Esta sencilla definición de quien era entonces jefe del Departamento de Edificaciones de la CTNE describe la función instrumental de la arquitectura en esta industria, servir de contenedor y proteger a los equipos y al personal encargado de operarlos.

La telefonía como negocio nació de la explotación de la patente de Alexander Graham Bell, registrada en marzo de 1876. En torno a ella se creó la compañía matriz American Telephone \& Telegraph (AT\&T) y una serie de operadoras regionales afiliadas, que se conocian de manera global como el Bell System. El servicio comercial se inauguró en New Haven (Conneticut) en enero de 1878, con 21 clientes (Bell Telephone System 2005: 31). Esta fue la primera central telefónica, instalada en un bajo comercial sin ningún requisito técnico específico.

El procedimiento para poner en contacto a dos clientes en ese periodo era por completo manual. La operadora conectaba ambas líneas utilizando un cuadro de conmutación muy simple, derivado de los que se usaban en telegrafia. El componente más pesado de la infraestructura era la batería que permite establecer el circuito de conversación. Por entonces se instalaban baterias individuales en cada domicilio, de manera que no había necesidades estructurales fuera de lo común, cualquier sala bien iluminada servía para convertirse en una central primitiva.
Con el crecimiento del negocio en las grandes ciudades apareció la necesidad de construir edificios telefónicos ad hoc. Se necesitaba espacio para instalar cuadros de conmutación mayores y para alojar cada vez más operadoras. Además, una peculiaridad de la red primitiva obligaba a hacerlo en los pisos superiores. El cableado urbano era aéreo, se distribuía por medio de postes o de estructuras denominadas caballetes en los tejados. Todos esos cables convergían en la central, y tenían que entrar por la cubierta. A esto se añadía el peligro de incendio, muy presente en esos dias, porque los equipos eran de madera y los cables se protegían con papel encerado.

A finales de los años ochenta del siglo XIX, las compañías de Estados Unidos empezaron a contratar el diseño de centrales con grandes estudios de arquitectura. Esta práctica aseguraba plazos breves tanto en la confección del proyecto como en su ejecución, algo imprescindible a la hora de planificar el despliegue de grandes redes urbanas.

El conjunto más destacado del momento es el de Nueva York. La Metropolitan Telephone and Telegrah Company encargó a Cyrus Eidlitz (1853-1921) cuatro centrales en la ciudad (King 1893: 210-214). Este estudio, con diferentes cambios de denominación, ha sido el más influyente en esta industria y ha seguido diseñando edificios telefónicos hasta el presente.

La central de mayor tamaño se construyó en Cortland Street (1885-1887). Tenía ocho plantas y la acometida de cableado era subterránea, una novedad en la que Nueva York fue pionera. Podía atender a 6000 clientes, para lo que se necesitaba un cuadro con 150 operadoras. 
Central de Cortland Street, Nueva York

Boceto del Bell Telephone Building, St. Louis (Missouri), 1889.

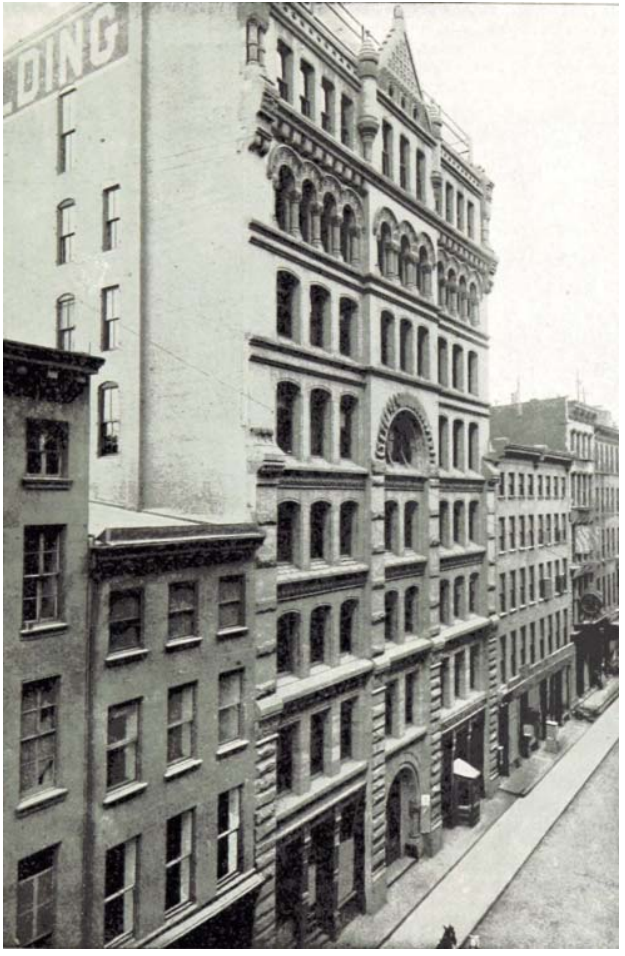

La construcción era de muro portante con estructura interior de hierro fundido recubierto a prueba de incendios. El aspecto exterior seguía la moda de los edificios comerciales de esa década. El gran arco de la calle central se hizo popular en la ciudad hacia 1850 por influencia británica. La decoración muestra el ascendiente de Henry Hobson Richardson (1838-1886) en esa generación de arquitectos. El ático se inspira en la Crane Library (Quincy, Massachusetts, 1882) y los pequeños arcos son de estilo "Richardsonian Romanesque".

Aún más próximos a Richarson eran sus discípulos directos y socios que fundaron el estudio Shepley, Rutan \& Coolidge en Boston. Suyo es el proyecto de la central telefónica de St. Louis, finalizada en 1889. El cuadro de operadoras se instaló en la última planta, que recibía iluminación natural por la galería de ventanas decoradas con los arcos característicos del lenguaje del maestro. La composición guarda una gran semejanza con una de sus obras su madurez, el edificio de oficinas Hayden (Boston, 1875).

Estos primeros grandes edificios telefónicos mostraban ya la tendencia al uso de lenguajes monumentales y a su utilización como iconos de las compañias propietarias. La planta solía tener forma de "L", lo que permitía disponer de una gran sala para las operadoras muy bien iluminada, mientras que los servicios quedaban recogidos en un extremo.
En 1896 se produjo una innovación técnica con impacto directo en los requisitos estructurales, la implantación del sistema de batería central. Se eliminaron las pilas domésticas y se concentró la alimentación eléctrica en el edificio telefónico. El peso de las baterías y elementoss auxiliares (generadores, rectificadores, etc.) es muy elevado por unidad de superficie. A esto se añadió a principios del siglo XX el comienzo de la instalación de equipos de conmutación automática, que sustituian a las operadoras en las comunicaciones urbanas. Son también muy pesados y requerian salas de 18 pies americanos (5,48 metros) de altura para su instalación. Las especificaciones de sobrecarga de los forjados de los nuevos edificios variaban entre los 750 $\mathrm{kg} / \mathrm{m}^{2}$, típicos para los equipos de conmutación, hasta los $1500 \mathrm{~kg} / \mathrm{m}^{2}$ para las salas de baterías, cifras propias de construcciones industriales.

Estos requisitos se convirtieron en invariantes del diseño de centrales y condicionaron su composición. La arquitectura telefónica podría haber asumido su naturaleza industrial y adaptar el aspecto externo a su función, pero no ocurrió así. Por el contrario, cristalizó una forma de trabajo en la que el estudio de arquitectura se comprometía a cumplir con las especificaciones técnicas y, a cambio, el diseñador disponía de una gran libertad para definir el cerramiento, bajo la condición de que la central no pareciese una factoría.

\section{Los edificios como herramienta de la politica de relaciones públicas}

En este punto conviene diferenciar los modelos de la arquitectura telefónica americana y europea a principios del siglo XX. Los regimenes de propiedad eran opues-

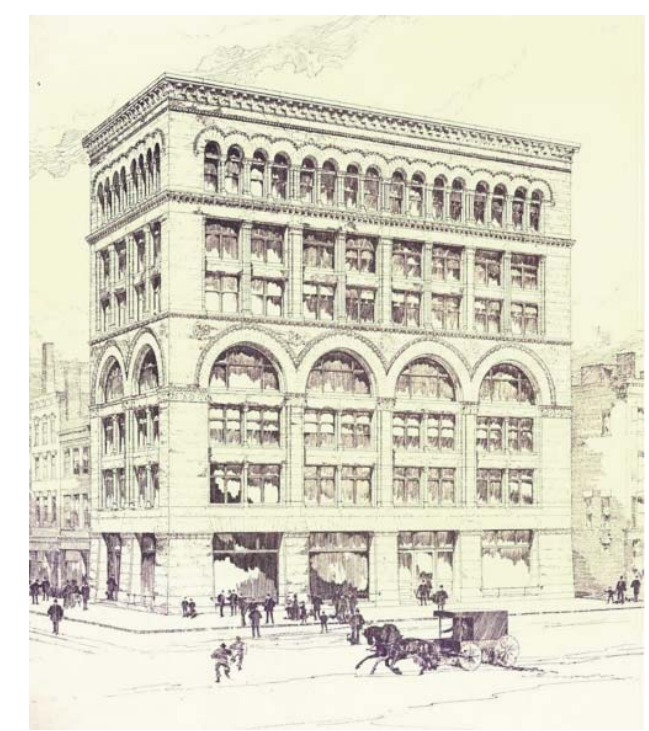



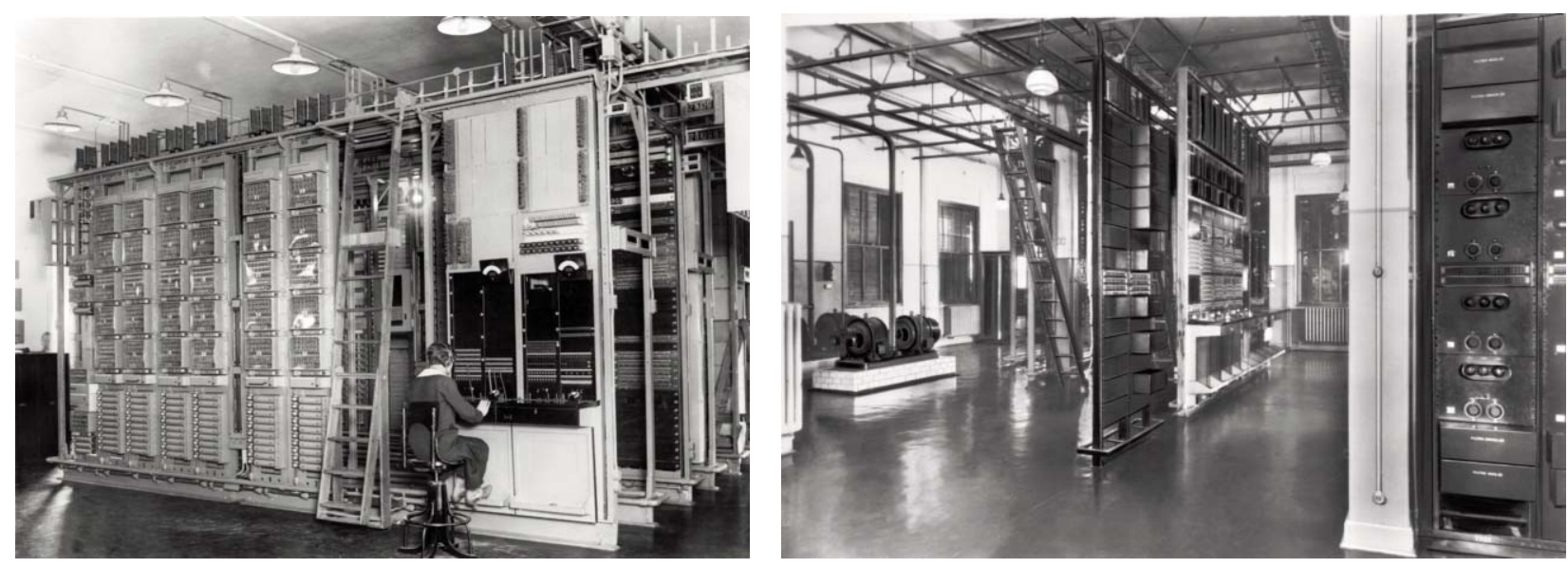

Izquierda. Mesa de vigilancia de la central de Bilbao, 1928.

Derecha. Repetidores en la central de Valls (Tarragona), 1929. tos. En Estados Unidos el Bell System era un monopolio de facto, de capital privado, mientras que en la mayor parte de Europa la telefonía terminó siendo absorbida por las administraciones postales. Hubo un evidente atraso en la extensión del servicio con respecto a América del Norte, hasta después de la II Guerra Mundial, con la única excepción de los países escandinavos. Las instalaciones telefónicas europeas utilizaban los edificios postales o de otros organismos de la administración, por lo que no se creó una política de imagen diferente a la del propio Estado.

"Las oficinas telefónicas europeas parecian más cuarteles que palacios. Sus muros y fachadas estaban desgastados y oscurecidos por el paso de los años y de la polución atmosférica que los había roído largo tiempo". (Chapuis 2003: 34)

El modelo americano terminó imponiéndose en todo el mundo a mediados del siglo $\mathrm{XX}$ y es el que estudiamos en esta investigación. No puede entenderse sin conocer la importancia de la política de relaciones públicas en el negocio telefónico de Estados Unidos.

Por su carácter casi monopolístico y un servicio deficiente, el Bell System no gozaba del aprecio público a principios de siglo. Además pesaba sobre la compañia la amenaza de la intervención estatal. Para conjurar estos peligros, se contrató al mejor estudio de publicidad, N. W. Ayer \& Son, de Nueva York, con un encargo insólito para la época. En lugar de vender un producto de lo que se trataba era de crear una imagen positiva de la marca mediante anuncios en prensa, libros escritos por encargo y otros recursos propagandísticos.

"Nunca una gran empresa se propuso de forma tan sistemática y decidida crear una imagen corporativa de sí misma como AT\&T en 1908. Y nunca una empresa logró cumplir su objetivo de forma tan triunfal". (Marchand 1998: 2).

La arquitectura fue una pieza más de la estrategia de relaciones públicas. Los publicistas del Bell System concedian gran importancia a los edificios como representación física de la compañia en cada población. Debían ser capaces de encarnar su solvencia técnica y financiera. Esta tendencia era ya habitual en las aseguradoras y bancos neoyorquinos de finales del XIX que contrataban sus proyectos a los estudios más prestigiosos. Ese era el entorno en el que se movian los ejecutivos de AT\&T $\mathrm{y}$ en el que se desarrollaron sus ideas sobre este particular.

Ya antes de la gran operación de imagen que comenzó en 1908, se había establecido otro principio importante, el de buena vecindad, por el que las centrales debían adoptar el aspecto del caserío en el que se construyesen. La razón no está del todo clara, aunque algunos investigadores lo relacionan con un episodio de rechazo muy fuerte a las infraestructuras telefónicas. ${ }^{1}$

Como se indicó en el apartado previo, en la telefonía primitiva todo el cableado era aéreo, sostenido por postes o estructuras de madera sobre los tejados. Con el aumento de la demanda, se crearon situaciones embarazosas.

"Algunas calles de las grandes ciudades se oscurecieron con los cables. [..] $\mathrm{Al}$ final, en la mayor linea de postes, construida en West Street, Nueva York, cada poste era un pino noruego que se elevaba noventa pies de la calzada, con treinta travesaños y trescientos cables". (Casson 1910: 126-127).

Esta situación solo se solucionó con el soterramiento de las líneas, un procedimiento mucho más caro que supuso un 


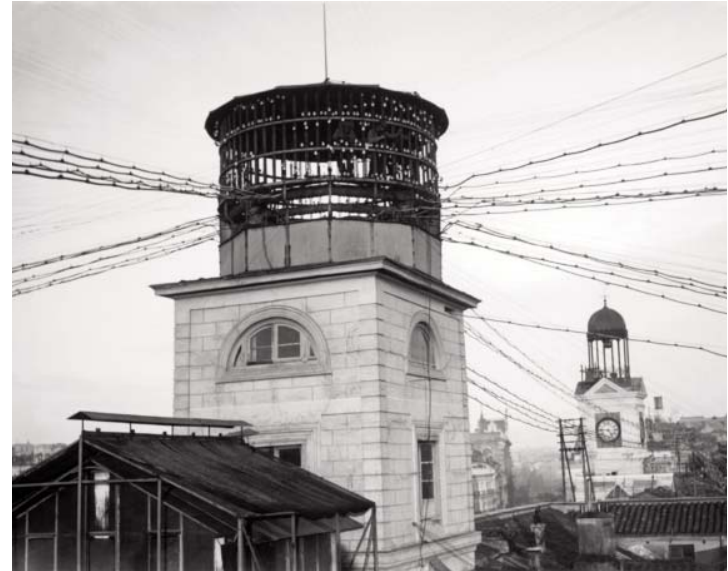

Izquierda. Cableado aéreo en el templete de la central de la calle Mayor, poco antes de su desmontaje, 1927.

Derecha. Postal de una central de barrio en Glens Falls (Nueva York) en los años 30.

Antigua sede de AT\&T en Broadway, Nueva York (1916-1923). Arquitecto: William Welles Bosworth. desgaste político para la compañia. De la disputa con las autoridades locales y el público, el Bell System aprendió una lección valiosa, el daño a la estética urbana perjudica el negocio. El principio de buena vecindad se convirtió en uno de los elementos clave de la arquitectura telefónica. ${ }^{2}$

Son numerosos los documentos en los que los arquitectos contratados por el Bell System mencionan esta necesidad. Un buen ejemplo de realización práctica es la relación que Holabird \& Roche estableció en Chicago con Illinois Bell a partir de 1908.

"Los diseños vagamente exóticos, ya fuesen georgianos o venecianos, podian también haber recordado al resto del mundo que ponía al alcance la nueva tecnología. Más importantes que las variantes exóticas eran las tranquilizadoras coincidencias. Aunque sus estilos nominales podian ser diferentes en apariencia, todas mostraban ciertas características que permitian reconocerlas de inmediato como edificios de un único cliente". (Bruegmann 1997: 428).

Holabird \& Roche ofrecía no solo la competencia técnica para lograr esa imagen unificada, sino también para cumplir de manera estricta con los planes de construcción. John Augur Jr., nieto del fundador, cifró en "veinte o treinta" los edificios que llegaron a construir por año para Illinois Bell, en el momento de más actividad, justo tras el final de la II Guerra Mundial (Benjamin 1993: 32). Otros estudios de primera linea que trabajaron para el Bell System fueron McKenzie, Voorhees \& Gmelin (sucesores de Eidlitz), en Nueva York; Smith, Hinchman \& Grylls en Detroit o Mauran, Russell \& Crowell en el Medio Oeste.
Además de mimetizarse con el entorno, los edificios telefónicos del periodo clásico se decoraban de manera muy lujosa, rayando en la ostentación, en las zonas abiertas al público. En la sala comercial y en el vestíbulo principal se usaban maderas nobles, mármol y bronce. El visitante, posible comprador de acciones, debía sentirse conmovido ante este despliegue de medios.

William Welles Bosworth (1869-1966), discipulo de Richardson, era un arquitecto que se había labrado su fama diseñando residencias para millonarios de la Costa Este. El entonces presidente de AT\&T, Theodore Vail, le escogió para llevar a cabo el proyecto arquitectónico más ambicioso de la compañia, la construcción de la sede matriz en Broadway, completada en 1923. Bosworth escribió:

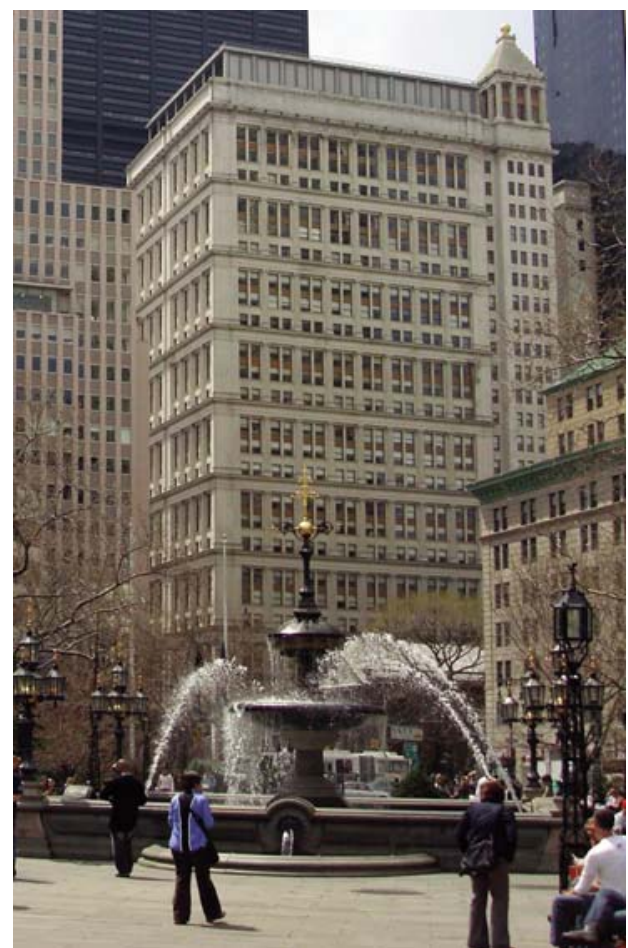


Barclay-Vesey Building (1923-1926). Arquitecto: Ralph Thomas Walker
"El propósito del señor Vail era que expresase el ideal que representa la compañía telefónica. Un gran servicio público de la más alta reputación, en el que la calidad, estabilidad y permanencia se sustentan en valores sólidos". (Harris 2006: 3)

La sede de Broadway refleja la personalidad erudita de Bosworth y sus inquietudes estéticas, muy alejadas del pragmatismo de los grandes estudios y de los creadores de centrales. ${ }^{3}$ El diseño exterior se articula en órdenes superpuestos. En la parte inferior, columnas dóricas colosales copia de las del Partenón. Sobre este cuerpo hay otros ocho, cada uno de ellos de tres pisos, con columnas jónicas, como las del templo de Artemisa en Sardis. Según el propio testimonio de Bosworth su modelo fue el Septizonium de Roma. El vestíbulo tenía fama de contener la mayor cantidad de mármol de cualquier edificio neoyorquino.

Este edificio, sin embargo, era una línea muerta del desarrollo arquitectónico. La época de los rascacielos columna tocaba a su fin. Tras el parón constructivo debido a la Gran Guerra, la arquitectura telefónica entró en su década prodigiosa, los "roaring twenties".

\section{La década dorada de la arquitectura telefónica}

Tras el final de la guerra, los Estados Unidos vivieron una etapa de gran prosperidad económica. En los años 20 nació la sociedad de consumo moderna, con la extensión del uso del automóvil o del frigorífico y el nacimiento de la radiodifusión. Uno de los elementos que ayudó a configurarla fue el teléfono. Hasta entonces había sido un artículo casi de lujo, reservado a las clases más pudientes y a los negocios, pero la generalización de la conmutación automática permitió que llegara a millones de hogares a un precio asequible.

Los equipos requerian nuevos edificios, a un ritmo desconocido hasta entonces, y en esa década los estudios vivieron una época dorada con un flujo continuo de pedidos. Para financiar la expansión de la red, el Bell System tenía que atraer nuevos pequeños accionistas que aportaran sus ahorros a cambio de una remuneración segura en forma de dividendos. Las relaciones públicas cobraron más importancia que nunca, bajo la dirección del vicepresidente Arthur W. Page, considerado uno de los padres de esta disciplina (Griese 2001: 89-125).

Posiblemente por el éxito como operación de imagen que había supuesto el rascacie- los de Broadway, los estrategas decidieron extenderla a las principales ciudades del país, capitales de sus compañias operadoras regionales que podian abarcar varios estados. En cada una de ellas se habría de construir un "Telephone Palace", que funcionase a la vez como gran central, oficinas y símbolo del poder de la compañía.

El primero de ellos, y el que tuvo más influencia, fue el rascacielos de la New York Telephone Company. El encargo recayó en el estudio McKenzie, Voorhees \& Gmelin, que se lo encomendó a uno de sus jóvenes empleados Ralph Thomas Walker (1889-1973). Walker habia presentado una propuesta de rascacielos al concurso del "Chicago Tribune" en 1922. Esta competición es famosa, entre otras cosas, por la propuesta que quedó en segundo lugar, la de Eliel Saarinen, muy elogiada por Louis Sullivan. El proyecto de Saarinen utilizaba retranqueos ("set-backs") en su composición, dando lugar a la característica forma de torre escalonada de los rascacielos neoyorquinos. La ciudad había publicado la "Zoning Law" en 1916, que obligaba a retranquear a partir de determinada altura para permitir la iluminación de calles y edificios anejos.

El proyecto de Walker fue el primer gran rascacielos con "set-backs" de Nueva York. Sobre una base trapezoidal que ocupa todo el solar y en la que se excavaron cinco niveles de sótano, se levanta un cuerpo de diez plantas, dedicado principalmente a equipos. Sobre él, otro en forma de " $H$ " de ocho pisos para oficinas, y coronando el conjunto una torre de doce plantas más,

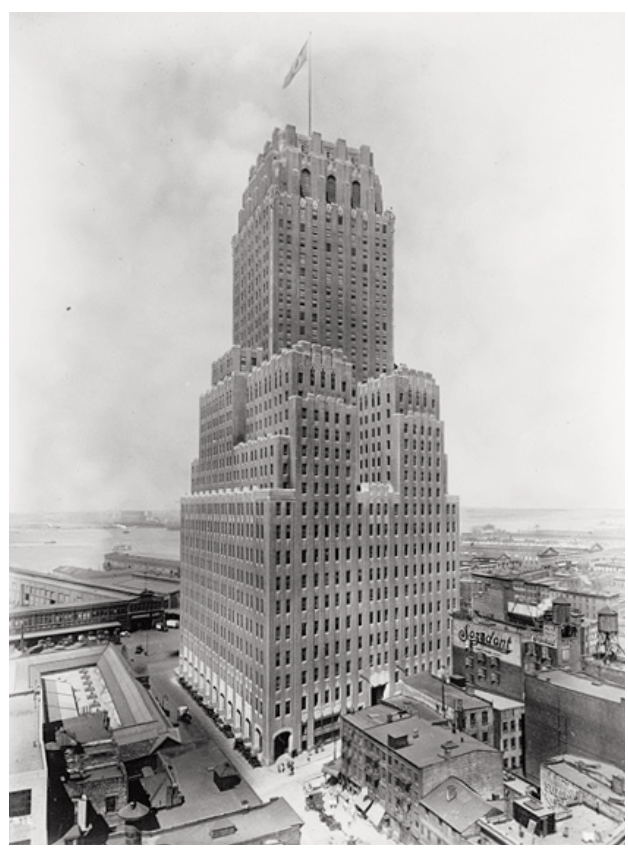


girada $45^{\circ}$ para alinearse visualmente con su vecino el Woolworth Builiding. Sus 150 metros y aspecto rotundo destacaban en el perfil del Bajo Manhattan. Se completó en 1926 y desde entonces se conoce como Barclay-Vesey por el nombre de las calles en que se emplaza. En la actualidad es la sede de Verizon, una de las compañías herederas de AT\&T y sigue funcionando como central.

El cerramiento exterior se hizo con ladrillo tipo "klinker" con un grosor medio de 12 pulgadas $(30,5 \mathrm{~cm})$, por necesidades de aislamiento térmico de los equipos, y ventanas a prueba de incendios. La decoración mezclaba motivos fitomorfos, zoomorfos y figuras naives de indigenas diseñadas por Walker. El autor obtendría resultados estéticamente mucho más refinados en sus diseños geométricos expresionistas de dos edificios telefónicos posteriores en la misma ciudad, el AT\&T Long Lines Building (1930) y la central de Willoughby Street (1929).

En planta baja se encuentra la mejor muestra de la ingenua iconografia telefónica.

"El vestíbulo de veintidós pies de altura estaba dominado por diez frescos pintados en el techo por Mack, Jenney \& Tyler 4 que ilustraban métodos de comunicación empleados a lo largo de la historia". (Arms Bzdak 1995: 78).

El foco de la alegoría principal es el Sol, en medio del cual se sitúa un teléfono, que

Izquierda. Postal de época con el Southwestern Bell Building, St. Louis, Missouri (1925).

Derecha. Bell Canada Montreal (1927-1929). Arquitecto: Ernest Isbett Barott. irradia su influjo benefactor. La cenefa decorativa se compuso con simbolos de circuitería eléctrica como relés, fusibles y lámparas. En los extremos, dos genios alados parecen sostener las magníficas lámparas de bronce. Esta asociación con las imágenes religiosas no es casual. Según el profesor Marchand, las instituciones más valoradas de principios del siglo $\mathrm{XX}$ en Estados Unidos eran las distintas iglesias, y los negocios aspiraban a obtener un reconocimiento social equivalente (Marchand 1998: 39). Para ello no dudaban en recurrir a motivos vagamente religiosos, como en el caso que nos ocupa, cuidándose de no rozar el límite de la blasfemia. ${ }^{5}$

El Barclay-Vesey se convirtió en el modelo de los palacios telefónicos del Bell System. Entre los más destacados cabe citar el zigurat de Saint Louis (Mauran, Rusell \& Crowell, 1925) y las estilizadas torres de San Francisco (Miller \& Pflueger, 1924) y Cleveland (Hubbell \& Benes, 1925). Conforme la década fue avanzando, el ArtDéco se fue imponiendo como estilo decorativo. Así sucede en las sedes de Newark (Ralph Thomas Walker, 1927) y de Minneapolis (Rhodes Robertson, 1930), aunque se mantuvieron lenguajes más conservadores como el Modern Perpendicular Gothic en Denver (William Bowman, 1927) o en el aracaizante rascacielos de Montreal (Ernest Isbett Barott, 1927), inspirado en el Mausoleo de Halicarnaso. La crisis de 1929 paralizó el desarrollo de algunos proyectos, como el de Atlanta (Marye, Alger \& Vinour, 1929) que quedó inconcluso, y ter-
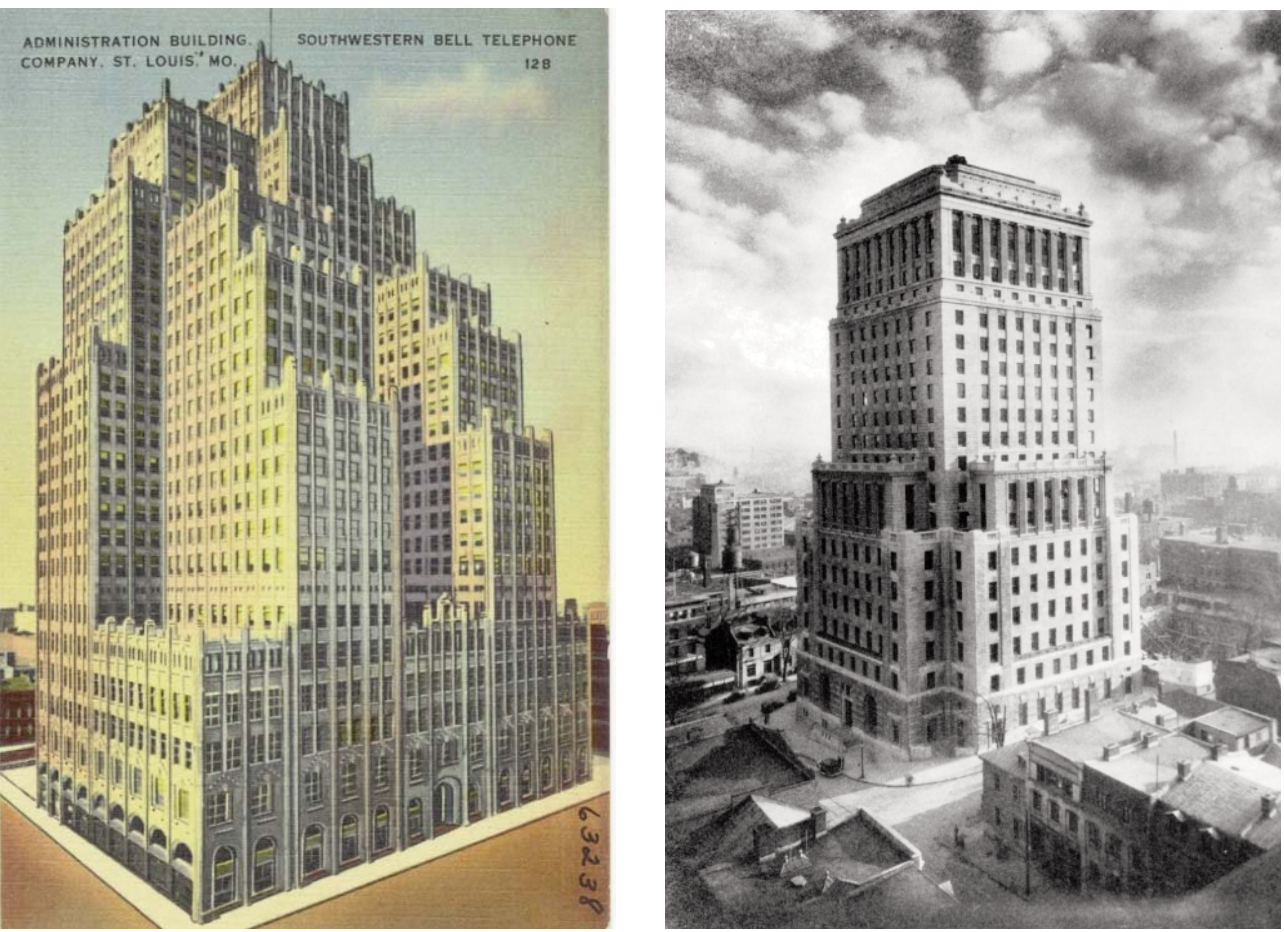
Principio de utilidad. Plano de la planta primera de la central telefónica de Tarrasa, 1932. minó con la década más extraordinaria de la arquitectura telefónica.

\section{Una exposición del modelo}

Existen numerosas citas en las publicaciones de AT\&T y en escritos de los arquitectos que trabajaron para la compañia sobre el valor de la arquitectura en el negocio. La mejor sintesis la escribió el editor de la revista The Bell Telephone Quarterly (Coe 1929). El artículo, de carácter divulgativo, comienza glosando la belleza de los palacios telefónicos de Nueva York y San Francisco, que no son "meras cajas de ladrillo como los rascacielos primitivos" sino que tienen "personalidad". Como principio básico menciona la adaptación de las centrales al entorno en el que se instalan. $\mathrm{Si}$ es en una ciudad, como una residencia más del barrio, si es en el campo, como una casa rural, y cita distintos estilos como el "Colonial" en Maryland y el "Spanish Style" en California o Arizona. Incluye como anécdota una central construida en estilo gótico al lado de una iglesia.

El trabajo contiene una exposición sistemática de los principios sobre arquitectura del Bell System. El primero es la utilidad, las centrales deben servir ante todo a su función técnica, basarse en planos tipo y ser de construcción y mantenimiento económicos. Le sigue en importancia la belle$\mathrm{za}$, tanto exterior como interior, entendida como un estilo armónico y menciona el protagonismo del Bell System en el desarrollo del "American Perpendicular" como entonces se conocía a lo que hoy llamamos "Art-Déco". La modernidad es otra de las

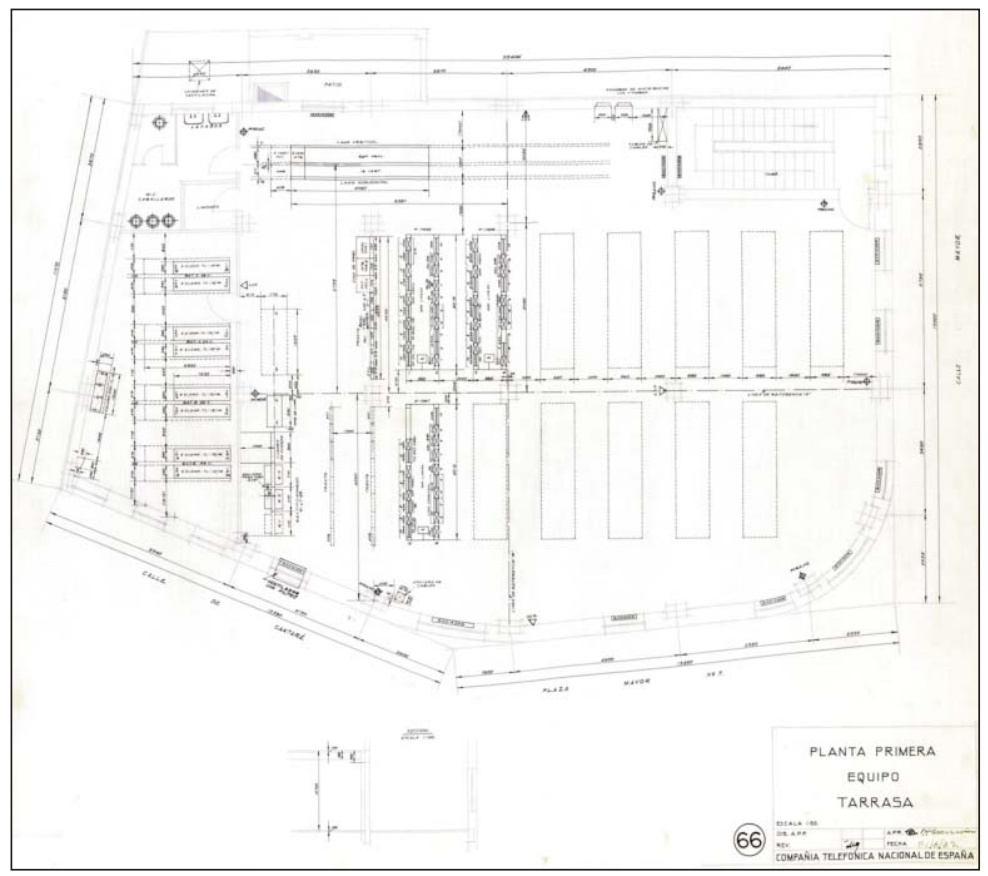

características de la arquitectura telefónica en opinión del autor, reflejada en dos vertientes, la de las instalaciones auxiliares como climatización y protección contra incendios y la decorativa. Esta última no debe entenderse como una adhesión a la vanguardia, por el contrario debe ser una modernidad "discreta".

Siguen los requisitos técnicos, como la solidez necesaria para albergar los equipos telefónicos y la previsión que permita ampliar en altura el edificio en el futuro. Esta idea es una de las más importantes de la arquitectura telefónica, las centrales se preveían para una vida útil larga, y las ampliaciones son muy comunes. No siempre se hicieron respetando el original, por lo que es habitual encontrar varios estilos superpuestos, en un fenómeno parecido al que se dio en las catedrales.

Las centrales debian reflejar, en opinión del autor, el espíritu de la compañia en su triple compromiso con los trabajadores, los clientes y los accionistas. A los primeros había que proporcionarles un entorno de trabajo agradable y productivo. Al resto, una muestra sólida de las capacidades técnicas y financieras para ofrecer un servicio de calidad y seguridad del retorno de la inversión.

Además debían ser reflejo del "espíritu americano" y despertar el orgullo ciudadano como el que producian los palacios telefónicos.

\section{E1 modelo americano trasplantado a España}

En 1924, el gobierno de Primo de Rivera concedió el monopolio de la telefonía a la Compañía Telefónica Nacional de España (en adelante, CTNE), a cambio de construir una red completamente nueva. La CTNE era filial de la neoyorquina International Telephone and Telegraph (ITT), sin ninguna relación accionarial con AT\&T. Era un emprendimiento personal de los hermanos Sosthenes y Hernand Behn, con el soporte financiero de los bancos Morgan y National, que pretendian construir una red de comunicaciones mundial. Por entonces controlaban la pequeña operadora de Puerto Rico y la más potente Cuban Telephone Company (Pérez Yuste 2004, Calvo 2010).

Los Behn desplazaron a Madrid a ejecutivos estadounidenses y cubanos que trabajaban según el modelo americano de negocio para implantarlo en España, convertida en una excepción en el panorama europeo de redes controladas por las adminis- 

en la central de Cádiz. Construcción de la estructura metálica, adaptada a la estética de la Calle Ancha y periodistas frente a la inauguración.
Tres caras de la arquitectura telefónica fachada exterior los equipos el dia de
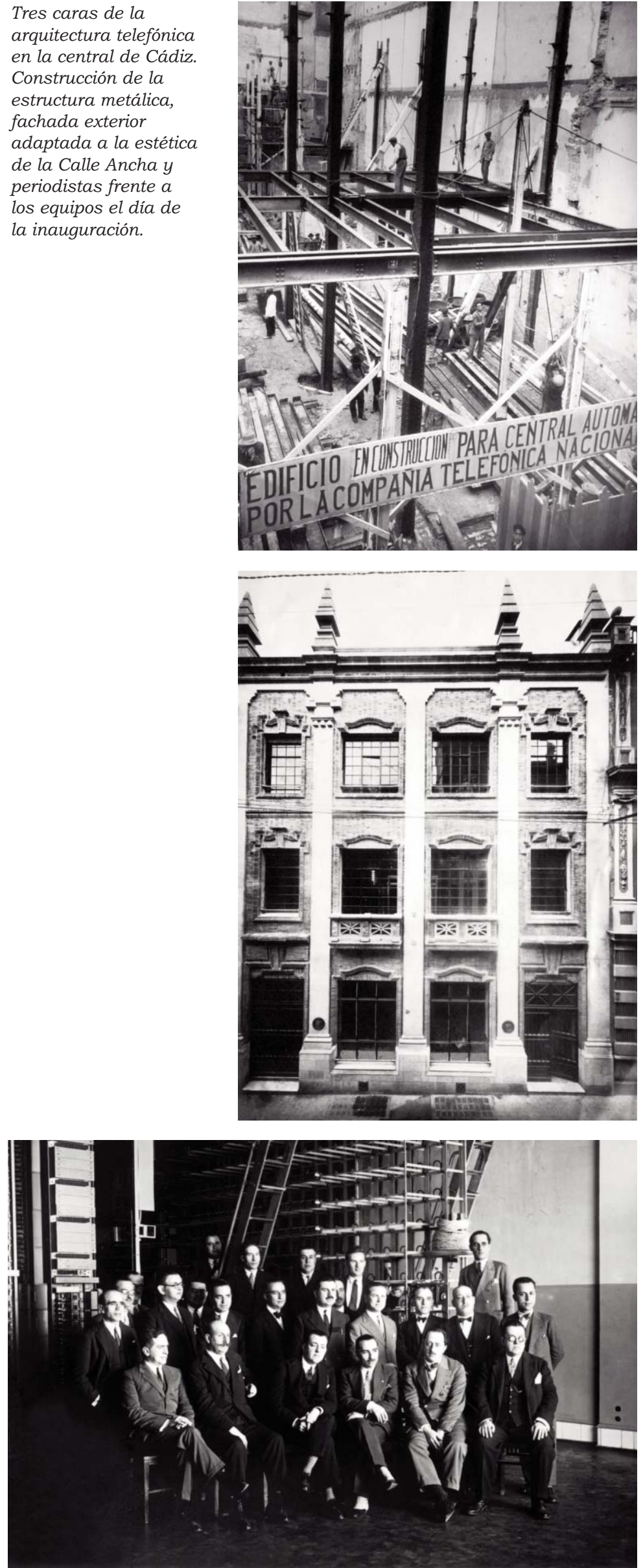

traciones postales. La arquitectura no escapó a esta influencia.

En el contrato firmado con el Estado, la CTNE se comprometía a construir en cinco años redes automáticas con canalizaciones subterráneas en 17 ciudades $^{6}$. Esto obligaba a tener los edificios terminados antes de que venciera el periodo.

"Como primer paso para proporcionar un servicio adecuado, se compraron solares para las centrales de Madrid, Barcelona y otras poblaciones. Las obras de los edificios comenzaron tan pronto como se pudieron preparar los planos y el contrato permitía”. (Bagwell 1945: 314).

En España no había experiencia en diseño de centrales y mucho menos un gran estudio similar a los estadounidenses con el que contratar el programa de construcción. Ante esta dificultad, se creó un Departamento de Edificaciones dependiente de Ingeniería, con arquitectos de plantilla y con la idea de que se organizase como uno de esos estudios de proyectos.

El control final estaba en manos de ITT. En el contrato privado entre la compañia americana y su filial española, la primera se reservaba derecho de tutela sobre los planos de las plantas de todos los edificios de nueva construcción. Esta cláusula aseguraba que los requisitos de ingeniería de equipos siempre iban a primar sobre cualquier otra consideración.

Al frente del Departamento de Edificaciones se nombró al recién titulado Ignacio de Cárdenas Pastor (1898-1970, t. 1924), que se rodeó de compañeros de generación. José María de la Vega Samper (1900-1979, t. 1924), fue su segundo y sucesor tras la Guerra Civil. Santiago Esteban de la Mora (1902-1988, t. 1926) y Ramón Aníbal Álvarez García-Baeza (1901-1980, t.1926) estuvieron en el departamento antes de unirse al GATEPAC. Muy desconocidos porque trabajaron casi en exclusiva para Telefónica son Luis Clavero Margatí (18991970), Paulino Justo Gayo Notario y el cubano Santiago García Claramunt. Este trío firmó la mayoría de las centrales anteriores a la Guerra Civil, junto a Cárdenas y de la Vega. Como procedimiento excepcional, se contrató al principio a arquitectos consagrados para algunas obras consideradas estratégicas. Las dos centrales de Sevilla las diseñó Juan Talavera Heredia (1880-1960, t. 1909); la de Málaga, Fernando Guerrero Strachan (1879-1930, t. 1904) y la de Cádiz, Francisco HernándezRubio (1859-1950, t. 1892). La de Barcelona la comenzó Francesc Nebot (18831965, t. 1909), tras un accidentado con- 
Planta segunda de la central Madrid "Norte", 1945.
Equipos instalados en la segunda planta de Madrid "Norte", 1945.

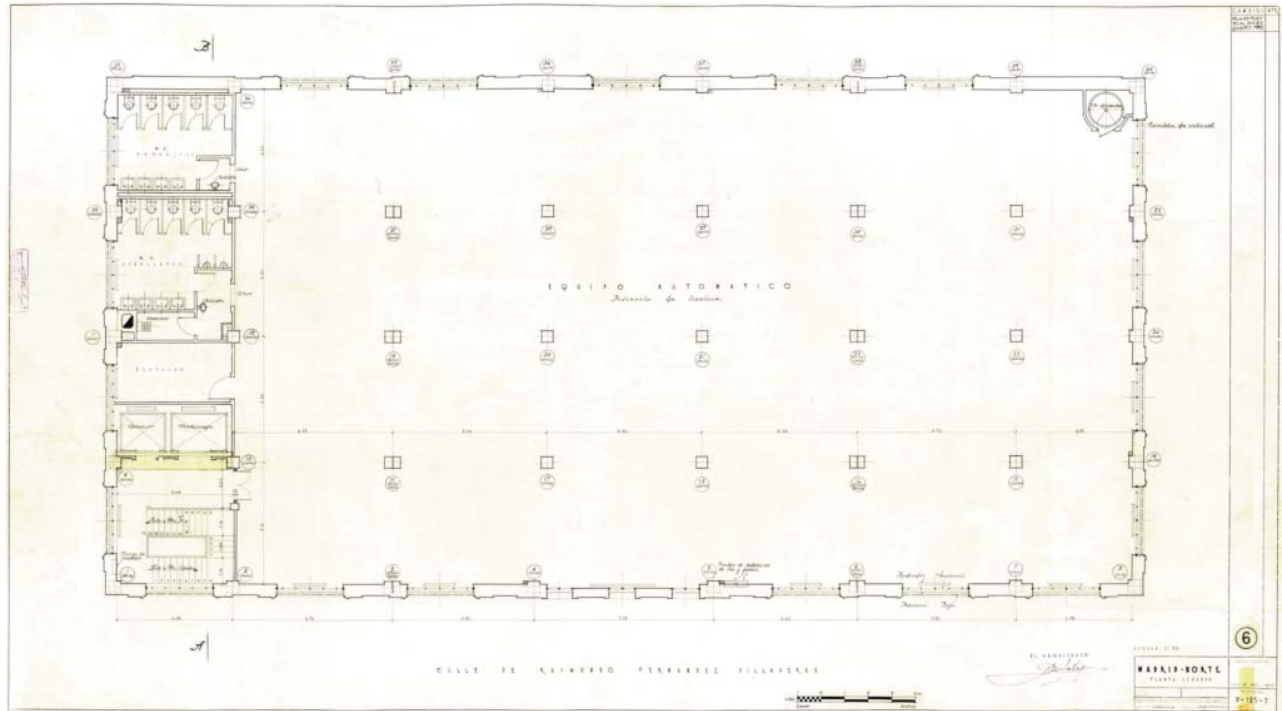

curso, aunque tuvo que terminar el proyecto Cárdenas.

Cárdenas viajó en 1925 a Nueva York, para recibir instrucciones del arquitecto jefe de ITT, Louis S. Weeks (1881-1971):

"Como los americanos estaban en la idea de que en España estábamos atrasadísimos en todo lo relacionado con la arquitectura moderna encontraron la solución a mi supuesta ignorancia enviándome a Nueva York, donde el arquitecto de la ITT me orientaría sobre ello". (Navascués 1984: 114-115).

En ese viaje debió de conocer el BarclayVesey Building en sus estados finales de construcción. Durante la estancia neoyorquina, Weeks y Cárdenas crearon el proyecto preliminar de Gran Vía que Cárdenas completó en solitario en Madrid.

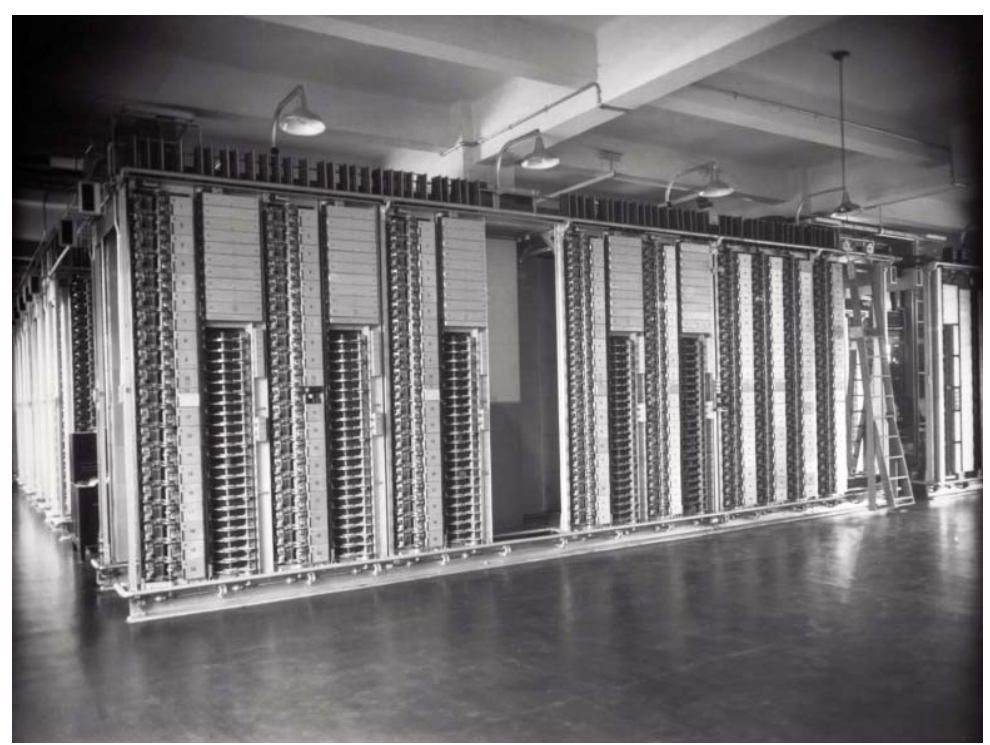

Lo más importante para esta investigación es comprobar como asimiló las ideas sobre la arquitectura en el negocio. Cárdenas dejó una colección reducida pero valiosa de artículos en publicaciones de Telefónica y en revistas especializadas, que junto a la citada conferencia de José María de la Vega de 1945, resumen la adopción del modelo americano.

Sobre el primero de los principios enunciado por Coe, la utilidad, ambos lo expresaron con claridad. Para de la Vega (1945) "si el edificio ha de ser central automática habrá de ser la Sección de Equipo del Departamento de Ingeniería la que dé las primeras referencias, ya que la instalación del equipo será la más importante en cuanto a extensión, coste y servicios".

Por su parte, Cárdenas, en las ya mencionadas memorias manuscritas, expresaba así esta prioridad:

"Las plantas o distribución interior son la parte más importante del proyecto, y esta distribución, en aquellos de nuestros edificios que han de alojar un equipo automático, está supeditada a que se monte en las mejores condiciones, sacrificando gustosos a menudo un mayor efecto decorativo".

La adecuación estilística al entorno es también mencionada por ambos arquitectos. Para de la Vega: "[el edificio] ha de responder al ambiente arquitectónico de la región o lugar en que esté enclavado".

En su obra se aprecia el virtuosismo con el que aplicó este principio. La central de Salamanca (1929) es un palacete plateresco y la de Vitoria (1931) una casa solariega vasca, pero también están la pequeña joya racionalista de León (1932) o la muy 


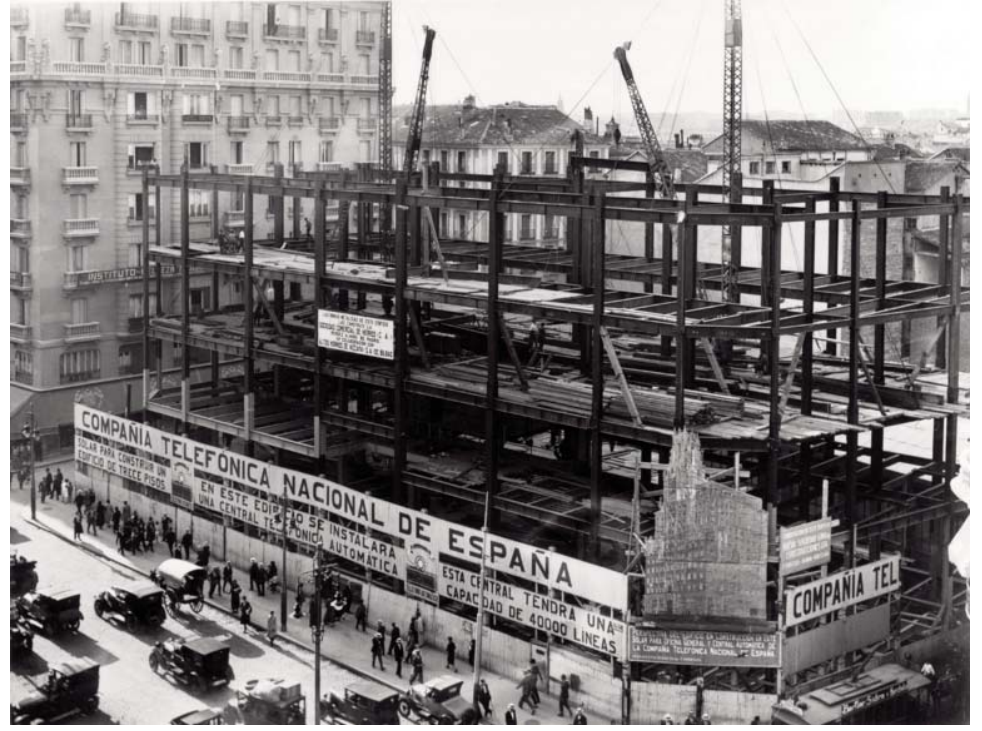

El edificio anuncio. La perspectiva del rascacielos es uno de los elementos publicitarios de esta valla de autopromoción que se atribuye a Kenneth McKim, primer director de publicidad de la CTNE, uno de los primeros directivos enviados por ITT.

Izquierda. Obras de la central de

Santander en 1926.

Derecha. Torréon "Monterrey" en la central de

Salamanca, 1929. industrial de Pamplona (1927), enclavadas ambas en zonas de ensanche.

Cárdenas lo expuso de una manera muy similar:

"La idea nacional de nuestra Compañia, se afirmará en las fachadas de sus edificios, las cuales pretendemos siempre que armonicen con el carácter peculiar de cada población”. (Cárdenas 1927: 17-18)

En el mismo artículo, Cárdenas resaltaba el valor representativo y propagandístico de las centrales y hablada del edificio anuncio. En la revista "Arquitectura" escribió sobre Gran Vía:

"El emplazamiento del edificio requiere, por ser un punto de gran circulación, un carácter muy ciudadano, con el empaque señorial del que quiere y puede hacer ostentación de, su riqueza y de su importancia”. (Cárdenas 1928: 42).
El rascacielos era el resumen de todas estas ideas, un "telephone palace" americano en medio de Madrid, que causó una honda impresión en el público. De la Vega se lamentaba en su conferencia de las exigencias de monumentalidad que imponían algunos ediles, lo que obligó a añadir elementos sin ninguna función como pequeñas torrecillas o pérgolas: "cualquier Ayuntamiento aspira a que el edificio de la Telefónica sea en su ciudad, lo que la Central de Gran Vía es en Madrid".

La visión de Cárdenas es más pragmática. En sus memorias escribió que los Behn habian dejado claros sus gustos: "tenía que proyectar un edificio que halagase al posible comprador de acciones, es decir a la masa burguesa y conservadora".

Leonardo Morales Pedroso (1887-1967), autor del rascacielos de la Cuban Telephone Company en La Habana (1927), recibió instrucciones parecidas:

"El Sr. Hernand Behn, Presidente de la Compañía, indicó a los arquitectos su deseo de que el edificio fuese una verdadera obra de arte y una de las más hermosas construcciones del país". (Morales 1927: 5)

La interiorización del modelo fue consecuencia natural de la organización de la CTNE, heredada de las operadoras regionales del Bell System. Atendiendo a los resultados, la actividad del Departamento fue un éxito. Desde su puesta en marcha en 1926 hasta 1932 se completaron 42 edificios para centrales automáticas de nueva planta. Entre ellos, todos del mayor porte como Madrid, Barcelona, Valencia, Zaragoza, Sevilla y Bilbao. Se superó con creces el compromiso del contrato de 1924.

Las consecuencias de la crisis de 1929 y de las tensiones con el primer gobierno de
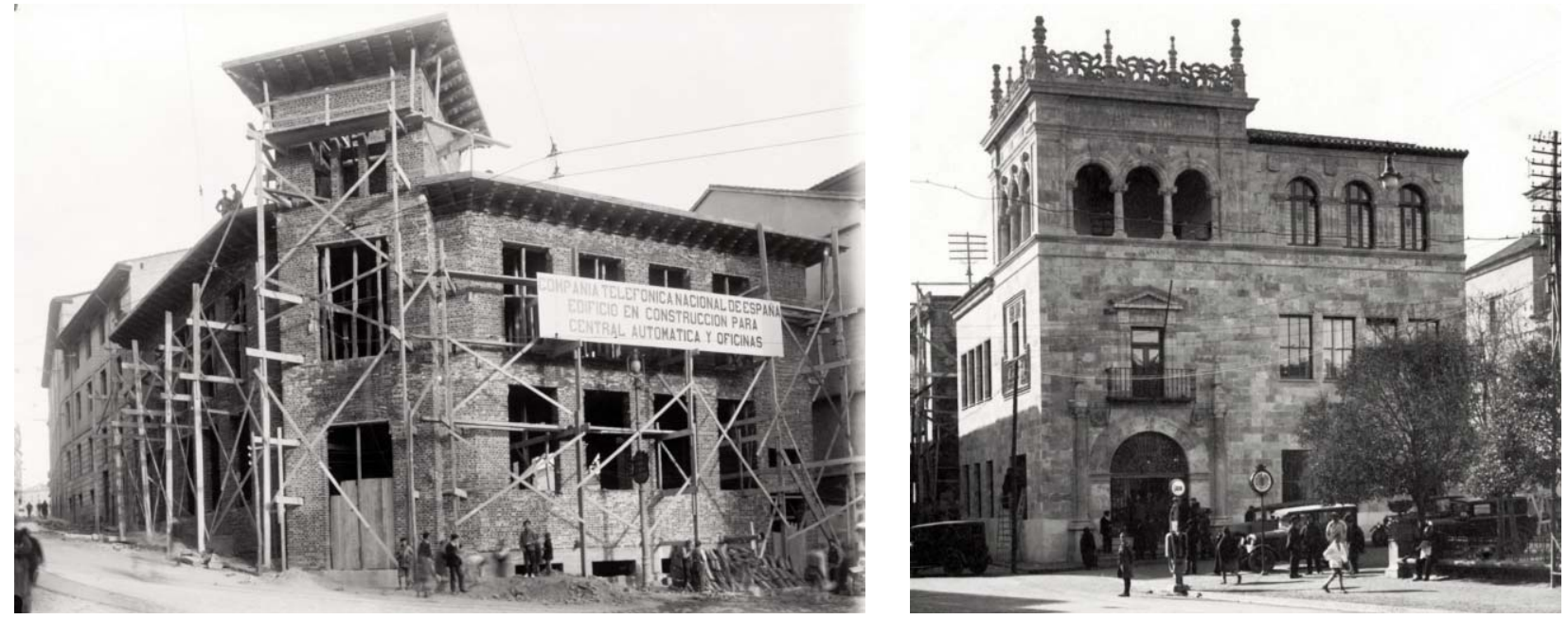


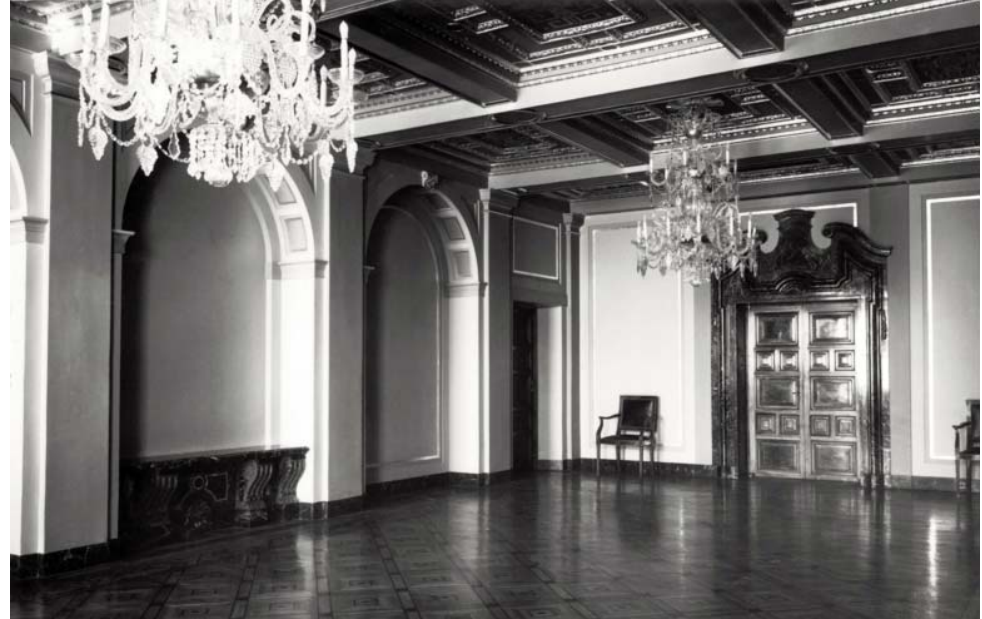

Lujo en la Sala del Consejo de Gran Vía.

Sede de la Cuban Telephone Company en La Habana. la República supusieron un parón de dos años. A partir de 1934 la actividad retornó a un ritmo inferior al del primer lustro. La Guerra Civil abrió un paréntesis constructivo del que la CTNE tardó dos décadas en salir.

\section{Conclusiones}

La arquitectura telefónica nació para servir como contenedor protector de los equipos que conforman la red. Peter Buchanan estableció una clasificación de seis tipos en función del grado de exposición de la naturaleza industrial al exterior. El primero es el del edificio que oculta de manera deliberada esa condición mediante su composición y cerramientos. En el extremo opuesto se encuentran las cadenas de producción visibles desde el exterior (Bucha-

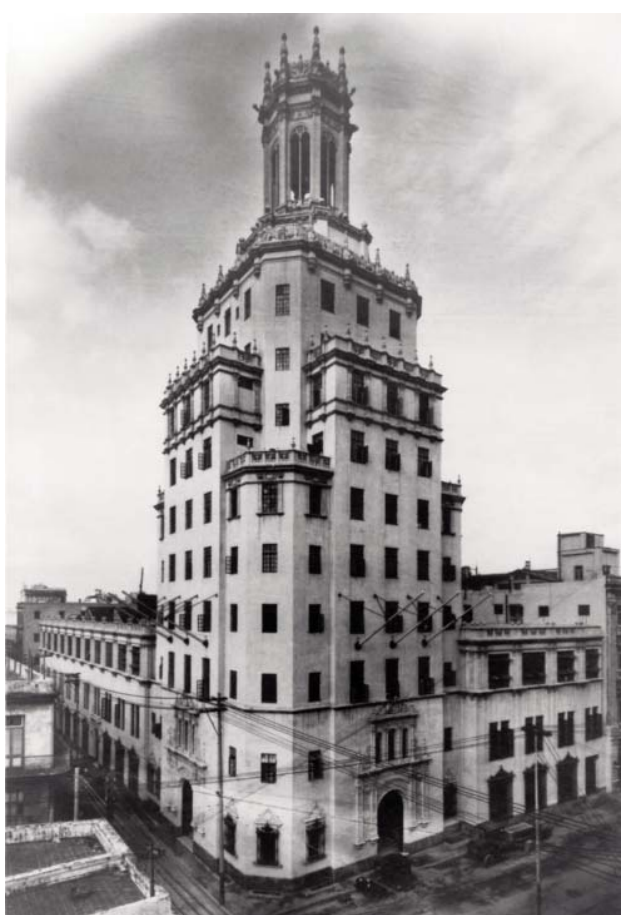

nan 1988). La arquitectura telefónica pertenece al primer grupo.

Junto al afán por no llamar la atención, convivía una pulsión exhibicionista muy marcada en los edificios singulares, para crear una escena de lujo y poder. Esta necesidad no obedecía a las necesidades del servicio, pero sí a las del negocio tal y como se concebía en los años 20 del siglo pasado en Estados Unidos.

De esta tensión surgió un tipo de construcción singular, el "Telephone Palace", a la vez factoría vertical oculta y tótem. Se caracterizaba por una segregación especial, funcional y estética muy marcada. En el exterior y zonas abiertas, derroche de materiales y ornamentación; en las salas de equipos, de imposible acceso para el público, desnudez formal y austeridad fabril. Este producto norteamericano llegó a España con la concesión del monopolio de la telefonía a ITT, por medio de su filial la CTNE, en 1924. El rascacielos de Gran Vía es la traslación a Europa con la única adaptación del estilo exterior neobarroco.

Esta manera de entender el papel de la arquitectura en el negocio telefónico llevó a las compañias propietarias a encargar sus proyectos a estudios de primera línea.

El desarrollo del programa de construcciones de la CTNE entre 1924 y 1936 no puede entenderse sin el modelo americano. El Departamento de Edificaciones se organizó al modo de un estudio de arquitectura estadounidense y los jóvenes profesionales contratados para ello adoptaron las ideas que venían del otro lado del Atlántico, aplicándolas con éxito. En este sentido, España supone una excepción en Europa, donde la telefonía era un servicio subsidiario de las administraciones postales que no crearon un lenguaje representativo diferente al del resto de edificios gubernamentales.

A través de los textos de los dos protagonistas más destacados del Departamento, Ignacio de Cárdenas y José María de la Vega, se descubren los mismos principios que en 1929 sintetizó Richard Storrs Coe en un artículo divulgativo del Bell System.

\section{Notas}

1. Es el caso de la profesora Claire Poitras, que aporta diversos testimonios de los arquitectos de Bell Canada, la filial del Bell System que daba servicio a Montreal (Poitras 2004: 87-98).

2. Este principio se mantuvo hasta después de la I Guerra Mundial. Cuando la evolución técnica aconsejó la construcción de muros ciegos, y se adoptaron lenguajes muy agresivos, como el 
brutalismo, hubo numerosos episodios de rechazo, tanto en Estados Unidos como en Europa. Para entonces las compañias habian abandonado gran parte de las ideas clásicas sobre la arquitectura telefónica, en favor de la productividad como principio director.

3. Era un profundo conocedor de la arquitectura clásica, y había estudiado nueve meses en Londres con el pintor Lawrence Alma-Tadema. Financiado por su cliente y benefector Rockefeller, dirigió obras de restauración en la catedral de Reims y en los palacios de Versalles y Fontainebleau.

4. La asociación de estos tres muralistas había decorado otros edificios corporativos como el de la Standard Oil, la biblioteca Morgan y la casa de John D. Rockefeller. Su obra más conocida son los frescos del Parlamento de Canadá en Ottawa (Downs 1940: 220).

5. El vestíbulo, como buena parte del edificio, sufrió graves daños el 11 de septiembre de 2001, ya que se encontraba justo enfrente de las Torres Gemelas y al lado de otro rascacielos destruido, el WTC 7. Según un informe de la FEMA, los factores que contribuyeron a su supervivencia fueron la solidez estructural, los gruesos muros de ladrillo que absorbieron la mayor parte de la energía y las medidas contra incendios, todo ello característico de la arquitectura telefónica (McAllister 2002). Fue objeto de una cuidada restauración que le valió varios premios en reconocimiento a la protección del patrimonio. Con motivo de su reapertura un periodista del New York Times, calificó el vestíbulo como la "Capilla Sixtina" del arte telefónico.

6. El texto del contrato puede consultarse en Gaceta de Madrid, núm. 241, 28 de agosto de 1924, p.1051-1057

https://www.boe.es/datos/pdfs/BOE/1924/24 1/A01051-01057.pdf

\section{Bibliografia}

Arms Bzdak, Meredith. 1995. The Architecture of Ralph Thomas Walker: 1919-1939. Tesis Doctoral. Director: Tod A. Marder. Rutgers, The State University of New Jersey.

Bagwell O. C., Parsons J. J. 1945. Twenty Years of Telephony in Spain. Electrical Communication, 22: 321-341.

Bell Telephone System. 1955. The Telephone in America, folleto divulgativo.

Benjamin, Susan S. 1993. Oral History of John Augur Holabird. Chicago Architects Oral History Project. The Art Institute of Chicago.

Bruegmann, Robert. 1997. The Architects and the City. Holabird \& Roche of Chicago, 1880-1918. Chicago: The University of Chicago Press.

Peter Buchanan. 1988. Constructing Order Ticino: obras recientes de Vacchini y Snozzi. The Architectural Review, 1095: 36-54.

Calvo, Ángel. 2010. Historia de Telefónica 1924-1975. Primeras décadas: tecnología, economía y política. Madrid: Ariel/Fundación Telefónica.

Cárdenas Pastor, Ignacio de. 1928. El Edificio de la Compañia Telefónica Nacional de España en Madrid. Arquitectura, 106: 42-46.

Cárdenas Pastor, Ignacio de. 1927, El Departamento de Edificios. Notas de su variada y acertada actuación. Revista Telefónica Española, 8: 1221.

Casson, Herbert Newton. 1910. The History of the Telephone. Chicago: A. C. McClurg \& Co.

Chapuis, Robert. 2003. 100 Years of Telephone Switching, 1878-1960's. IOS Press.

Coe, Richard Storrs. 1929. Bell System Buildings - an Interpretation, The Bell Telephone Quarterly, VIII: 201-217.

Vega Samper, José María de la. 1945. El diseño y distribución de edificios telefónicos y su construc ción, conferencia número 18 de la II Reunión de
Jefes Técnicos, Madrid: CTNE.

Downs, Joseph. 1940. Water Colors of Early American Houses. The Metropolitan Museum of Art Bulletin, 35: 220-223.

Harris, Gale. 2006. American Telephone and Telegraph Building, 195 Broadway. NYC Landmarks and Preservation Comission. LP-2194.

King, Moses. 1893. King's handbook of New York City; an outline history and description of the American metropolis. Boston.

McAllister, Therese et al. 2002. Peripheral Buildings. En FEMA: "World Trade Center Building Performance Study. Data Collection, Preliminary Observations, and Recommendations".

Morales, Leonardo. 1927. El Nuevo Edificio de la Cuban Telephone Company. Revista Telefónica Cubana, 2: 5-7.

Mumford, Lewis. 1937. What is a City?, Architectural Record, 82:185.

Navascués, Pedro; Fernández, Ángel Luis et al. 1984 El edificio de la Telefónica. Madrid, Espasa Calpe.

Pérez Yuste, Antonio. 2004. La Compañía Telefónica Nacional de España en la Dictadura de Primo de Rivera (1924-1930). Tesis Doctoral. Directora: Magdalena Salazar Palma. Universidad Politécnica de Madrid.

Poitras, Claire. 2004. L'expression architecturale de la notion de service public chez l'industrie du téléphone nord-américaine avant 1940. En Les territoires de l'entreprise / The Territories of Business. Québec: Presses de l’Université Laval.

\section{Referencias de imágenes}

Figura 1. Mapa de París con las siete centrales telefónicas y sus zonas de servicio en 1906. Colección de la Bibliothèque historique des Postes et des Télécommunications (BHPT). Licencia CC Attribution-ShareAlike 3.0 Unported (CC BY-SA 3.0) https://upload.wikimedia.org/wikipedia/commons / 1/11/R\%C3\%A9seau_t\%C3\%A91\%C3\%A 9phonique de Paris en_1906\%28archives_BH PT\%29.jpg?1459502716395

Figura 2a. Construcción de la central telefónica de Málaga en 1928. Arquitecto: Fernando Guerrero Strachan. A la izquierda puede verse parte de la Puerta del Sol de la Catedral. Fotógrafo: Francisco Sáchez. Fuente: Archivo Histórico Fotográfico de Telefónica, negativo R-00965.

Figura 2b. Central de la Plaza Nueva, 1928. Arquitecto: Juan Talavera Heredia. Fotógrafo: Dubois. Fuente: Archivo Histórico Fotográfico de Telefónica, negativo R-00809.

Figura 3. Fachada de la central de la Metropolitan Telephone and Telegraph Company en Cortland Street, Nueva York, 1895. Arquitecto: Cyrus Eidlitz. (Moses 1893: 217). Fuente: British Library.

Licencia: This work is in the public domain in its country of origin and other countries and areas where the copyright term is the author's life plus 70 years or less. This work is in the public domain in the United States because it was published (or registered with the U.S.Copyrigh Office) before January 1, 1923. https://commons.wikimedia.org/wiki/File:\%28King1893NY C\%29_pg217 METROPOLITAN TELEPHONE A ND_TELEGRAPH_COMPANY_\%28TELEPHONE_BUILDING,_CORTLANDT_STREET\%29.jpg

Figura 4. Boceto del Bell Telephone Building, St. Louis (Missouri), 1889. Arquitectos: Shepley, Rutan \& Coolidge. Publicado originalmente en American Architect and Building News, enero de 1889 Fuente: Wikimedia Commons.

Licencia: This image is in the public domain in the United States. In most cases, this means that it was first published prior to January 1, 1923.

https://en.wikipedia.org/wiki/File:Bell_Telephone_Building_in_1889_\%28St._Louis,_Missouri\%29.jpg 
Figura 5a. El interior de una central. Mesa de vigilancia de la central de Bilbao, 1928. Fotógrafo: Espiga. Fuente: Archivo Histórico Fotográfico de Telefónica, negativo R-02642.

Figura 5b. Repetidores en la central de Valls (Tarragona), 1929. Fotógrafo: Guri. Espiga. Fuente: Archivo Histórico Fotográfico de Telefónica, negativo R-02890.

Figura 6a. Cableado aéreo en el templete de la central de la calle Mayor, poco antes de su desmontaje, 1927. Fotógrafo: Alfonso.

Fuente: Archivo Histórico Fotográfico de Telefónica, negativo R-02006.

Figura 6b. Postal de una central de barrio en Glens Halls (Nueva York) en los años 30, en estilo neo georgiano muy común en la Costa Este. Editorial T.J. Kennedy Co. Fuente: Boston Public Library.

Licencia: Attribution 2.0 Generic (CC BY 2.0) https://www.flickr.com/photos/boston_public_ library/6922185882/in/photostream/

Figura 7. Anitgua sede de AT\&T en Broadway, Nueva York (1916-1923). Arquitecto: William Welles Bosworth. Fuente: Wikimedia Commons.

Licencia: Attribution-ShareAlike 3.0 Unported (CC BY-SA 3.0)

https://en.wikipedia.org/wiki/195_Broadway\#/media/File:15_Park_Row.JPG

Figura 8. Barclay-Vesey Building (1923-1926). Arquitecto: Ralph Thomas Walker. Fuente: Library of Congress.

Licencia: Public Domain.

https://www.loc.gov/item/det1994022033/PP /

Figura 9. Postal de época con el Southwestern Bell Building, St. Louis, Missouri (1925). Arquitectos: Russel, Mauran \& Crowell. Fuente: Boston Public Library.

Licencia: No known copyright restrictions. No known restrictions on use. https://www.digitalcommonwealth.org/search/commonwealth:xs5 $5 \mathrm{mf} 93 \mathrm{~h}$

Figura 10. Bell Canada, Montreal (1927-1929). Arquitecto: Ernest Isbett Barott. Fuente: McCord Museum, referencia MP-1989.15.16.

Licencia: Public Domain. https://en.wikipedia.org/wiki/Bell_Canada\#/media/File:Bell_Tel ephone_Building_1931.jpg

Figura 11. Principio de utilidad. Plano de la planta primera de la central de Tarrasa, 1932. La disposición de los equipos de conmutación define el trazado del edificio. Arquitecto: Luis Clavero Margatí.

Fuente: Fondo documental histórico de la Fundación Telefónica.

Figura 12a. Construcción de la central telefónica de Cádiz, 1928. Arquitecto: Francisco HernándezRubio. Fotógrafo: Marín.

Fuente: Archivo Histórico Fotográfico de Telefónica, negativo R-00851.

Figura 12b. Fachada a la Calle Ancha de la central de Cádiz. Arquitecto: Francisco Hernández-Rubio. Fuente: Archivo Histórico Fotográfico de Telefónica, negativo R-05450.

Figura 12c. Retrato de un grupo de periodistas el día de la inauguración de la central de Cádiz frente al equipo automático. Fotógrafo: Leonardo. Fuente: Archivo Histórico Fotográfico de Telefónica, negativo R-01503.

Figura 13a. Plano de la planta segunda de la central de Madrid "Norte", 1945. Arquitecto: José María de la Vega Samper. Planta diáfana para equipos. La escalera y servicios auxiliares se concentran en un extremo. En la parte superior derecha, puede verse una pequeña escalera de caracol de servicio.

Fuente: Fondo documental histórico de la Fundación Telefónica.

Figura 13b. Equipos instalados en la segunda planta de Madrid "Norte", 1945.

Fuente: Archivo Histórico Fotográfico de Telefónica, negativo R-02883.
Figura 14a. El edificio anuncio. La perspectiva del rascacielos es uno de los elementos publicitarios de esta valla de autopromoción que se atribuye a Kenneth McKim, primer director de publicidad de la CTNE, uno de los primeros directivos enviados por ITT, 1927.

Fuente: Archivo Histórico Fotográfico de Telefónica, negativo R-04908.

Figura 14b. La central de Santander fue la primera en terminarse. Imagen de 1926, con el cartel habi tual en todas las obras de la CTNE. Arquitecto: Ignacio Álvarez Meana.

Fuente: Archivo Histórico Fotográfico de Telefónica, negativo R-03360.

Figura 15. Torréon "Monterrey" en la central de Salamanca, 1929. Arquitecto: José María de la Vega Samper.

Fuente: Archivo Histórico Fotográfico de Telefónica, negativo R-05462.

Figura 16. Lujo en la Sala del Consejo de Gran Vía. Fuente: Archivo Histórico Fotográfico de Telefónica, negativo R-05495.

Figura 17. Rascacielos de la Cuban Telephone Company, La Habana, 1927. Arquitectos: Leonardo y Luis Morales Pedroso.

Fuente: Archivo Histórico Fotográfico de Telefónica, negativo R-04396.
Fecha final recepción artículos: 24/04/2016

Fecha aceptación:

19/06/2016

Artículo sometido a revisión por dos revisores independientes por el método doble ciego. 